\title{
Artemisinin: A Promising Adjunct for Cancer Therapy
}

\author{
Yamna Waseem $^{1}$, Choudhary A. Hasan ${ }^{1}$, Furqan Ahmed ${ }^{2}$ \\ 1. Internal Medicine, Dow University of Health Sciences (DUHS), Karachi, PAK 2. Surgery, Dow University of Health \\ Sciences (DUHS), Karachi, PAK
}

Corresponding author: Yamna Waseem, yamna_wr@hotmail.com

\begin{abstract}
Artemisinin is a herb derived from Artemesia annua (also known as sweet wormwood) and is known for its use as effective antimalarial pharmacotherapy. Recent studies have shown that artemisinin has antiangiogenic and growth inhibition effects, as well as an apoptotic ability secondary to its inherent endoperoxidase activity.
\end{abstract}

Categories: Infectious Disease, Oncology

Keywords: artmesinin, cancer, malaria

\section{Editorial}

Cancer is a leading cause of non-communicable deaths in Pakistan. With an aging population, the burden of the disease is expected to upsurge, making cancer a potentially significant health burden and adding to the burden of diseases in a developing country like Pakistan [1]. Even though recent advancements in oncological therapies have shown great promise, these carry with them a massive healthcare cost. As a result, these therapies showcase limited use in a low-income country, where the majority of the patients bear their own medical expenses.

It is essential that the mode of therapy employed in cancer treatment has favorable potency, efficacy, and little to no side effects on the normal cells of the body. Although advanced medical care for cancer treatment promises improved survival rates and complete cure, the burden of adverse effects on quality of life has led to hesitancy and patient disapproval for various cancer care modalities. Until recently, a Chinese medicinal herb traditionally called qing hao or sweet wormwood, which has artemisinin, a lactone component of the Artemisia annua plant, as its active ingredient has shown promising results as an anticancer pharmacological intervention. The compound artemisinin has been used actively as a potent antimalarial drug, as well as boost the immune system and treat liver conditions [2]. Further research on this compound revealed that the anticancer mechanism of artemisinin is similar to its antimalarial mechanism, thereby being activated by heme, an iron-containing compound. Artemisinin has an endoperoxide moiety that forms free radicals when it reacts with iron, and the formation of free radicals mediates cellular damage and apoptosis of cells containing abnormally high levels of iron. Due to rapid cell division and the high metabolism rate of cancer cells, the high levels of iron intake constitute artemisinin as a targeted therapy for cancer and make cancer cells more susceptible to the cytotoxic effects of the compound [3]. A specific dosage for maximum efficacy is yet to be established; however, as a general principle, 400 to $800 \mathrm{mg}$ per day can be used for at least six to 12 months, with no apparent adverse effects [2].

○ Copyright 2018 Waseem et al. This is an open access article distributed under the terms of the Creative Commons Attribution License CC-BY 3.0., which permits unrestricted use, distribution, and reproduction in any medium, provided the original author and source are credited.
Artemisinin is invariably a valuable compound to combat cancer and its effectiveness is enhanced by the fact that is it effective orally and is cheap, as compared to other pharmacological interventions available on the market. It produces fewer side-effects, which makes it a favorable option for treatment in low-income settings where cancer has deep roots, mainly because of expensive treatments and the reluctance to opt for traditional regimens for cancer [3]. Furthermore, a recent study conducted by Lin Qingsong et al. found that the addition of aminolevulinic acid (ALA) enhances the anticancer properties of artemisinin against colorectal cancer cell lines [4]. Thus, if a purposeful plan is devised to develop artemisinin compounds as an adjunct to use in cancer treatments, it will contribute to decreasing financial costs for medical therapies. Given that more than 25 species of artemisinin are found in Pakistan [5], oncologists in Pakistan should take advantage of this drug and explore its benefits in the treatment of various cancers.

\section{Additional Information}

\section{Disclosures}

Conflicts of interest: In compliance with the ICMJE uniform disclosure form, all authors declare the following: Payment/services info: All authors have declared that no financial support was received from any organization for the submitted work. Financial relationships: All authors have declared that they have no financial relationships at present or within the previous three years with any organizations that might have an interest in the submitted work. Other relationships: All authors have declared that there are no 


\section{Cureus}

other relationships or activities that could appear to have influenced the submitted work.

\section{References}

1. Sarwar MR, Saqib A: Cancer prevalence, incidence and mortality rates in Pakistan in 2012 . Cogent Med. 2017, 4:1288773.

2. Artemisinin for cancer treatment and prevention . (2018). Accessed: September 23, 2018 : https://nootriment.com/artemisinin-for-cancer/.

3. Lai H, Sasaki T, Singh NP: Targeted treatment of cancer with artemisinin and artemisinin-tagged ironcarrying compounds. Expert Opin Ther Targets. 2005, 9:995-1007. 10.1517/14728222.9.5.995

4. Wang J, Zhang J, Shi Y, et al.: Mechanistic investigation of the specific anticancer property of artemisinin and its combination with aminolevulinic acid for enhanced anti-colorectal cancer activity. ACS Cent Sci. 2017, 3:743-750. 10.1021/acscentsci.7b00156

5. Mannan A, Ahmed I, Arshad W, Asim MF, Qureshi RA, Hussain I, Mirza B: Survey of artemisinin production by diverse artemisia species in northern Pakistan. Malar J. 2010, 9:310. 10.1186/1475-2875-9-310 